\title{
Quarterly Summary Report April-June1978 \\ Process for Cleaning and Removal of Sulfur Compounds From Low BTU Gases
}

July 1978

Prepared for the U.S. Department of Energy under Contract EY-76-C-06-1830

Pacific Northwest Laboratory Operated for the U.S. Department of Energy by 


\title{
NOTICE
}

This report was prepared as an account of work sponsored by the United States Covernment. Neither the United states nor the Department of Energy, nor any of their employees, nor any of their contractors, subcontractors, or their employees, makes any warranty, express or' implied, or assumes any legal liability or responsibility for the accuracy, completeness or usefulness of any information, apparatus, product or process diselosed, or represents that its use would not infringe privately owned rights.

The views, opinions and conclusions contained in this report are those of the contractor and do not , necessarily represent those of the United States Government $\propto$ the United States Department of Energy.

\author{
PACIFIC NORTHWEST LABORATORY \\ operated by \\ BATTELLE \\ for the \\ UNITED STATES DEPARTMENT OF ENERGY \\ Under Contract EY-76-C-06-1830
}

Under Contract EY-76-C-06-1830

Printed in the United States of America

Available from

National Technical Information Service

United States Department of Commerce

5285 Port Royal Road

Springfield, Virginia 22151

Price: Printed Copy \$ *; Microfiche $\$ 3.00$

\begin{tabular}{|r|r|}
\hline$\bullet$ Pages & $\begin{array}{c}\text { NTIS } \\
\text { Selling Pric }\end{array}$ \\
\hline $001-025$ & $\$ 4.00$ \\
$026-050$ & $\$ 4.50$ \\
$051-075$ & $\$ 5.25$ \\
$076-100$ & $\$ 6.00$ \\
$101-125$ & $\$ 6.50$ \\
$126-150$ & $\$ 7.25$ \\
$151-175$ & $\$ 8.00$ \\
$176-200$ & $\$ 9.00$ \\
\hline $201-225$ & $\$ 9.25$ \\
\hline $226-250$ & $\$ 9.50$ \\
\hline $251-275$ & $\$ 10.75$ \\
\hline $276-300$ & $\$ 11.00$ \\
\hline
\end{tabular}


QUARTERLY SUMMARY REPORT

APRIL-JUNE 1978

PROCESS FOR CLEANING

AND REMOVAL OF SULFUR COMPOUNS

ROM LON BTU GASES
R. H Moore
D. G. Ham
D. $H$ Mitchell
R. J. Robertus
G. E. Stegen

July 1978

Prepared for the U.S. Department of Energy under Contract EY-76-C-06-1830

Pacific Northwest Laboratory

Richland, Washington 99352 


\section{$\underline{\text { CONTENTS }}$}

I. OBJECTIVE AND SCOPE OF WORK PHASE IV . . . . . . . . . . . 1

II. SUMMARY. . . . . . . . . . . . . . . . . . . . . 1

III. TECHNICALPROGRESS . . . . . . . . . . . . . . . . . 3

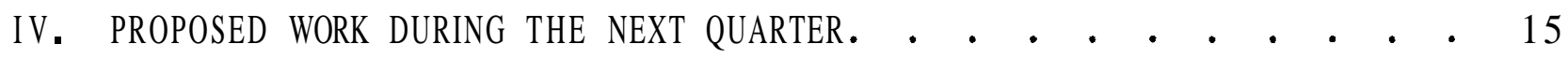

V. OVERALl PROJECT STATUS. . . . . . . . . . . . . . . . 15 


\section{QUARTERLY SUMMAYY REPORT}

APRIL-JUNE 1978

PROCESS FOR CLEANING AND REMOVAL

OF SULFUR COMPOUDS FROM LON BTU GASES

R. H. Moore, D. G. Ham, D. H. Mitchell, R. J. Robertus and G. E. Stegen

I - OBJECTIVE AND SCOPE OF WORK PHASE I V

In this phase of work the Process Development Unit (PDU) is to be remodeled by incorporation of appropriate subsystems to permit operation in continuous process mode. The PDU will be operated for a period of time sufficient to demonstrate process viability.

\section{SUMMARY}

1) Following repair of the gas preheater, Run C-8 was initiated on 4/11/78. All systems were placed in simultaneous operation; however, the regenerator was operated only about 40 minutes when a salt overflow forced a shutdown. The extraction section was continued in operation with good overall sulfur recovery until a plugged venturi orifice caused shutdown after about 4 hours.

2) A post mortem on Run C-8 disclosed salt had overflowed the regeneration column in serious quantities. The 1.5-in. alonized carbon steel $\mathrm{H}_{2} \mathrm{~S}$ exhaust line was completely plugged over a distance of about $8 \mathrm{ft}$ and partly filled with salt at numerous points. Salt had entered the secondary combustor It had also flowed into the steam $/ \mathrm{CO}_{2}$ inlet line and into the steam $/ \mathrm{CO}_{2}$ preheater. Considerable effort was required to repair this damage.

3) In further efforts to avert plugging of the venturi salt inlet orifice, the 1 -in. long by 114-in. diameter orifice was reamed to a conical shape with a 1/4-in. diameter outlet. This should be self-relieving and resistant to plugging. Provision for mechanical reaming was also made during the course of this work; so if plugging should occur, a rod can be pushed in to remove the obstruction. 
4) Run C-9 was initiated on $4 / 26 / 78$ and the extraction section operated without plugging of the venturi orifice. During this run we were able to confirm our growing suspicion that the regeneration column was plugged and located the plug at the 6th tray. It was necessary to suspend run C-9 when a failed trace heater caused the feed line and valve to the extraction column to freeze, effectively shutting down all salt flow.

5) After cool down from Run C-9, the regeneration column was washed with nitric acid to remove the salt and then washed cyclicly and exhaustively with water and steam. It was not possible to effectively wash the plugged tray, however, and the column section containing this tray has been removed.

6) Inspection of the column internals shows little or no corrosion has occurred. The alonized surfaces are discolored but no pitting or erosion/ corrosion is evident. The blind section containing tray number 6 will be opened, cleaned as required, and rewelded.

7) The venturi feed line was rewired to put the heaters on a 208-volt circuit (reduced from 240 volts) and faulty heaters on the upper pot drain line were repai red.

8) Run C-10 was initiated on 5/22/78. Immediate difficulties were experienced when another trace heater on the upper pot drain line failed causing several hours delay for repair. When repairs were complete, salt was directed to the venturi feed tank which filled. When flow to the venturi scrubber was initiated it was found the venturi feed line had ruptured and it was necessary to terminate the run.

9) Fol lowing Run C-10 the venturi feed line was repaired. New trace heaters were installed and wired in two separate circuits. These and the upper pot drain circuit were connected through newly installed variable transformers to their control circuits. In Run C-17, no potential higher than 100 volts was applied and operation was satisfactory.

10) Prior to the start of Run $\mathrm{C}-10$ the gland on the lower slide valve at the base of the lock hopper was repacked. This valve sees fairly high temperatures and may be distorting. The gland was leaking badly during run C-9. 
11) Run C-11 was initiated on 6/5/78. The run extended over a period of 84 hours with the gasifier in operation for 72 hours. All systems were in operation about 24 hours. This is the first time near steady state operation of the molten salt scrubber/regenerator has been achieved. A mass of data has been acquired but has not been completely analyzed.

12) Run C-12 was initiated in the late evening of 6/25/78 and terminated in the morning of 6/29/78. All systems were operated and good performance data acquired. The run was marred by operational difficulties associated with attempts to bleed off salt. Salt found its way into the 3 -in. Iine which connects the gas preheater to the venturi scrubber and several hours were spent in clearing this problem. The run was terminated when salt flow to the regenerator could not be maintained due to a plugged section of the salt cooler.

13) In the interval between runs $\mathrm{C}-11$ and $\mathrm{C}-12$ the leaking slide valve gland at the base of the lock hopper was repacked, the secondary burner was disassembled, cleaned, and a faulty control mechanism replaced. The lower pot furnace has lost one or two elements and has been rewired to allow operation at about 67 percent of normal capacity. This will be adequate. All trace heaters found to be damaged during run $\mathrm{C}-11$ were replaced.

\section{II - TECHNICAL PROGRESS}

Following repairs to the gas preheater, run C-8 was initiated on $4 / 11 / 78$ with the objective to establish operation of all systems. Heat up of all trace heaters began shortly after midnight and by 6:45 a.m. the gasifier was readied for startup. By 8:00 a.m. $800 \mathrm{lb}$ of coke had been added to $50 \mathrm{lb}$ of preignited charcoal. By 10:00 a.m. it was necessary to add steam to the inlet air to control the gasifier temperatures.

At 1:50 p.m. salt flow to the venturi was initiated with immediate flow response and flow was maintained until 2:00 p.m. to fill the corase de-entrainer at which time the venturi feed was valved off. This was necessary because the siphon leg which connects the regeneration column to the salt makeup pot still contained a plug of frozen salt and the regeneration column could not be started. 
At about 3:00 p.m. the upper siphon allowed flow and feed to both the venturi and the regenerator was initiated. Immediate restart was obtained. During the period from 3:00 p.m. to 3:50 p.m. the regeneration column was being brought on line with spurts of salt being added and gas flow being interrupted occasionally to allow the trays to prime. Toward the end of this period it was noted that the AP on the top tray of the absorber was abnormal so the gas flow was valved off momentarily to allow this tray to prime. At this point it was necessary to valve off salt flow to the venturi (4:05 p.m.) which was tending to flood and the venturi orifice plugged and flow could not be restarted. This eventually resulted in a decision to shut down.

The next morning, however, a steam purge introduced via the $\mathrm{CO}_{2}$ purge entry to the salt inlet orifice sufficed to clear this orifice and it became evident if the residual heat in the gasifier was sufficient immediate restart was possible. This was achieved about 1:30 p.m. and by 2:30 p.m. an additional 800 ib of coke was added and at 5:07 p.m. salt flow to the venturi was initiated with immediate flow response. Meanwhile, salt flow to the extraction column was initiated at 3:55 p.m. and to the regenerator at 4:47 p.m. so as of 5:07 p.m. all systems were operating. Problems with the regenerator were apparent because the AP a t trays 6 and 7 was much too high and was erratic. Suddenly a $5: 45$ p.m. salt leaked from a flange in the $\mathrm{H}_{2} \mathrm{~S}$ exhaust line above the regeneration column and it was obvious the column was flooding. The leaking salt plugged the $\mathrm{H}_{2} \mathrm{~S}$ exhaust line as it froze so the regeneration column became inoperable. Operation of the extraction section was continued until 8:40 p.m. when the venturi salt inlet orifice again plugged and the run was terminated shortly after this occurred.

The salt overflow from the regeneration column produced serious damage:

- The 1.5-in $\mathrm{H}_{2} \mathrm{~S}$ exhaust line had to be replaced by a stainless steel line fabricated by PNL crafts.

- Portions of the 3/4-in. SS steam inlet line were refabricated and replaced. 
- The 8-in. diameter SS pail ring packed heat exchanger referred to as the steam $/ \mathrm{CO}_{2}$ preheater was half filled with salt which had to be leached out with nitric acid.

- The ceramic burner block in the base of the secondary combustor had to be replaced.

- All of the $\Delta P$ sensor lines and analytical sample lines leading from the regeneration column were plugged with salt and had to be freed of salt. To reduce future occurrences of such spills, a check valve was installed in the steam $/ \mathrm{CO}_{2}$ inlet line between the preheater and the column. A trap was also installed in the $\mathrm{H}_{2} \mathrm{~S}$ exhaust line.

The erratic operation of the venturi, due to plugging of the 114-in. diameter $\times 1$-in. long inlet orifice, continued despite the purge $\mathrm{CO}_{2}$ which was being introduced near the middle of the orifice. In our experience the orifice had plugged both downstream and upstream of this purge inlet. It was therefore decided to ream the orifice to a tapered orifice with an inlet of 114-in. diameter (which serves to restrict the flow) to an outlet of 112-in. diameter. This configuration should be self-relieving.

To accomplish this, 3116-in. diameter drills in 16-in. lengths were procured and using the 114-in. diameter $x 1$-in. orifice as a guide, a pilot hole was drilled through the back side of the venturi spool piece. This was enlarged to 518-in. diameter by drilling back from the outside and then the reamer was used to expand the orifice. Finally, a pipe was welded over the 518-in. hole and capped. A poker rod can be inserted hers and used to poke obstructions out of the venturi inlet orifice if needed.

Despite these operating difficulties run C-8 did provide data on the performance of the extraction section. Data taken during the first day's run and over a period of about 3 hours is collected in Table 1. All of the samples taken within the extraction column (A-0, A-1, A-2) show very high sulfur removal efficiency was achieved. The G-3 (final product) sample does not look as good as samples taken within the column. This sample point is in the exit gas line about 6 to $8 \mathrm{ft}$ beyond the packed bed de-entrainer becomes saturated with sulfur 
TABLE 1. Extraction Section Sulfur Removal Performance, Run C-8 on $4 / 11 / 78$

\begin{tabular}{|c|c|c|c|c|c|c|}
\hline Time & Sample & Sample Description & $\begin{array}{l}\text { COS } \\
\mathrm{ppm}\end{array}$ & $\begin{array}{l}\mathrm{H}_{2} \mathrm{~S} \\
\mathrm{ppm} \\
\end{array}$ & $\begin{array}{c}\text { COS Removed, } \\
\% \\
\end{array}$ & $\mathrm{H}_{2} \mathrm{~S}$ Removed, \\
\hline $1: 14$ p.m. & $G-1$ & Gasifier outlet gas & 173 & 436 & -- & -- \\
\hline $1: 41$ p.m. & $v-1$ & At coarse de-entrainer & 83 & 81 & 52.0 & 81.0 \\
\hline $1: 57$ p.m. & $A-2$ & Above top tray extrn. col. & 9 & 33 & 94.8 & 92.4 \\
\hline 2:08 p.m. & G-1 & Gasifier outlet gas & 175 & 368 & -- & -- \\
\hline $2: 24$ p.m. & $V-1$ & At coarse de-entrainer & 9 & 63 & 94.9 & 82.9 \\
\hline $2: 43$ p.m. & $A-1$ & Above bottom tray, extrn. col. & 9 & 14.5 & 94.9 & 96.1 \\
\hline $2: 52$ p.m. & $V-1$ & At coarse de-entrainer & 12 & 37 & 93.1 & 89.9 \\
\hline 3:04 p.m. & $A-0$ & Below bottom tray, extrn. col. & 9 & 12 & 94.9 & 96.7 \\
\hline $3: 17$ p.m. & $V-1$ & See above & $1 ' 1$ & 39 & 93.7 & 89.4 \\
\hline $3: 33$ p.m. & $G-2$ & $\begin{array}{l}\text { Between gas preheater and the } \\
\text { venturi inlet }\end{array}$ & 134 & 405 & -- & -- \\
\hline $3: 44$ p.m. & $G-3$ & Final product gas & 18 & 60 & 86.6 & 85.0 \\
\hline $3: 55$ p.m. & $V-1$ & See above & 12 & 97 & 91.0 & 76.0 \\
\hline $4: 09$ p.m. & $G-3$ & Final product gas & 14 & 59 & 90.0 & 85.0 \\
\hline 4:53 p.m. & $G-1$ & See above & 201 & 494.8 & -- & \\
\hline
\end{tabular}


compounds during periods when gas is flowing but salt is not flowing. It tends to give back sulfur to the clean gas coming off the top tray of the extraction column. This is a transient effect and is not expected to be a problem.

Data taken during the second day's operation are shown in Table 2. Samples were taken over about a 4-hour period and again the extraction section gave excellent sulfur recovery.

$\mathrm{H}_{2} \mathrm{~S} / \mathrm{COS}$ ratios in the gas can vary considerably from run to run and with time depending on circumstances such as fuei being gasified, gasifier status (fuel burden, temperature, steam rate, etc.) and purge gas volume. The marked effect of dumping 15 SCFM of $\mathrm{CO}_{2}$ purge gas into the system (done inadvertantly) is shown by G-2 samples at 6:57 p.m. and 7:09 p.m. $\operatorname{COS}$ is formed by reaction between $\mathrm{CO}_{2}$ and $\mathrm{H}_{2} \mathrm{~S}$.

A few samples were taken from the regeneration column but without data on the salt composition it is uncertain at this writing how meaningful the results were. When the column "flooded" (actually it was plugged), excess salt filled the sample lines in the upper half of the column rendering these inoperable. Operating difficulties tend to engage the attention of our analysts, reducing the rate of data acquisition.

Run C-9 was planned with the objective of determining whether the regeneration column was operable or not. The run was initiated on 4/26/78. The trace heating was started about 3:00 p.m. and trouble was immediately encountered when the venturi feed line failed to heat. An electrician was held over and repairs were completed about 7:00 p.m. The gasifier was started about midnight and with arrival of the day shift everything appeared to be ready for initiztion of salt flow. When the venturi feed valve was opened, however, no flow resulted. Purge gas flows indicated the salt inlet orifice was clear and a search with a "clamp-on" ammeter disclosed a faulty trace heater. A cold spot was located with a thermocouple probe at the heater location so insulation was removed and the heater replaced.

Heating was resumed and about 12:00 noon attempts to start salt flow were resumed and again it was found that the same small heater had failed once more. Additional insulation was added and by 4:00 p.m. the salt plug melted and salt flow was obtained. 
TABLE 2. Extraction Section Sulfur Removal Performance, Run $\mathrm{C}-8$ on $4 / 12 / 78$

\begin{tabular}{|c|c|c|c|c|c|c|}
\hline Time & Sample & Sample Description & $\begin{array}{l}\mathrm{COS}, \\
\mathrm{ppm}\end{array}$ & $\begin{array}{l}\mathrm{H}_{2} \mathrm{~S}, \\
\mathrm{ppm}\end{array}$ & $\begin{array}{c}\text { COS Removed, } \\
\%\end{array}$ & $\begin{array}{c}\mathrm{H}_{2} \mathrm{~S} \text { Removed, } \\
\end{array}$ \\
\hline 3:22 p.m. & G-1 & Gasifier outlet gas & 75 & 11 & -- & -- \\
\hline 3:39 p.m. & G-1 & Gasifier outlet gas & 123 & 139 & -- & -- \\
\hline 4:05 p.m. & G-1 & Gasifier outlet gas & 118 & 72 & -- & -- \\
\hline 5:13 p.m. & $v-1$ & Coarse de-entrainer & 22 & 22 & 82 & 84 \\
\hline 5:32 p.m. & $A-2$ & Above top tray extrn. col. & 9 & 12 & 93 & 91 \\
\hline 5:46 p.m. & G-3 & Final product gas & 18 & 22 & 85 & 84 \\
\hline 6:05 p.m. & $v-1(a)$ & See above & 42 & 45 & 66 & 68 \\
\hline $6: 22$ p.m. & $A-1$ & Above bottom tray extrn. col. & 10 & 12 & 92 & 91 \\
\hline $6: 34$ p.m. & $v-1$ & See above & 39 & 28 & 68 & 80 \\
\hline $6: 57$ p.m. & $G-2^{(b)}$ & Between gas preheat and venturi & 335 & 134 & -- & -- \\
\hline 7:09 p.m. & $G-2^{(b)}$ & Between gas preheat and venturi & 464 & 190 & -- & -- \\
\hline $7: 23$ p.m. & $V-1$ & See above & 208 & 112 & -- & -- \\
\hline 7:35 p.m. & $A-2$ & See above & 10 & 12 & 94 & 97 \\
\hline $7: 47$ p.m. & $A-1$ & See above & 9 & 11 & 94 & 97 \\
\hline 7:57 p.m. & $A-0$ & Below bottom tray extrn. col. & 75 & 12 & 53 & 96 \\
\hline $8: 10$ p.m. & G-2 & See above & 159 & 377 & -- & -- \\
\hline $8: 22$ p.m. & $V-1$ & See above & 77 & 103 & 52 & 73 \\
\hline $8: 34$ p.m. & $A-2$ & See above & 9 & 16 & 94 & 96 \\
\hline $8: 48$ p.m. & $A-1$ & See above & 9 & 19 & 94 & 95 \\
\hline
\end{tabular}

(a) Sample taken just prior to start of venturi scrubber.

(b) $\mathrm{CO}_{2}$ purge gas left on. Caused high $\mathrm{COS}$ at expense of $\mathrm{H}_{2} \mathrm{~S}$. Compare with 8:10 p.m. sample which is normal. 
Salt flow to the extraction column was also started and after about 10 minutes it was clear that the top tray in the extraction column had not primed and it was necessary to bypass gas flow for a few seconds to allow sufficient accumulation of salt to prime the tray. This also required valving off flow to the venturi. When attempts to restart flow to the venturi were made, it was plugged at the orifice. The cap was removed from the newly installed entry to this orifice and the orifice was rodded out and at 5:15 p.m. reliable flow to the venturi was obtained. Despite the cold spot in the venturi feed line, no further flow problems were experienced at the venturi except those caused by operator error. For example, during the early morning hours of the 28th the operator unknowingly allowed the venturi to flood. With full salt flow, the AP across the venturi sometimes exceeds the 2 psi limit of the gage. A slight increase in gas flow will produce an on scale reading by blowing the accumulating salt up through the venturi exhaust line to the coarse de-entrainer. This operator was not aware of this and began to search for reasons why the gage was pegged. Tank level readings finally convinced him he was losing salt to the lower (emergency) reservoir. This gage has been replaced with one with greater range so this error will be less likely to occur in the future.

A this point (2:30 a.m.) salt flow was valved off while $80 \mathrm{lb}$ of fresh salt was charged to the upper pot to replace losses. When operation was resumed about 5:00 a.m., it was found that the valve to the extraction column was frozen and trace heaters on this valve and adjacent line had failed. This effectively shut down all salt flow.

Meanwhile, operation of the regeneration column had disclosed that the risers on either tray 6 or 7 were plugged. This was deduced from the behavicr of the AP gages which now function smoothly and reliably. The gage measuring the pressure drop across these trays gives an abnormally high reading and cycles between about 6 and $10 \mathrm{in}$. $\mathrm{H}_{2} \mathrm{O}$. Gas flowing up the column is trapped below the plugged risers and builds pressure sufficient to drive salt back up the downcomer. This relieves the pressure for an instant and the salt reseals causing the pressure to build again. 
As the gas flow is increased, the AP gage pegs out at $10 \mathrm{in} . \mathrm{H}_{2} \mathrm{O}$ and remains pegged. With this much pressure the gas flows continuously up the downcomer (because it cannot go up the risers) and salt is prevented from flowing down. With continued addition of salt, the column will overflow as happened during runs $\mathrm{C}-5$ and $\mathrm{C}-8$. The only way salt can make it through the column is with low or no gas flow. By deliberate flow manipulation it was possible during this run to build up an excessive accumulation of salt above tray 6 and then dump it down the column and into the salt makeup pot. This, of course, is not a practical operating mode. This behavior convinced us of the necessity to repair the column and contributed to the decision to shut down the run following the heater failure on the extraction column feed valve.

In the period following this run the small heaters on the venturi feed 1ine have a11 been replaced and have been rewired to reduce the applied voltage and, therefore, the applied stress. This should result in improved reliability performance.

The regeneration colum has been leached with nitric acid to remove all salt. It has been exhaustively washed and flushed with steam introduced via a jet inserted through the sample ports. This steam jet impinges with considerable force on the trays, walls, etc. All this failed to free the obstructed risers. Finally, the column has been taken apart and the center section containing the blocked risers removed. The top and bottom sections have been joined giving 4 trays instead of 8 . Water/air tests show this shortened version functions properly and in a few days PDU operation will be resumed.

It will be necessary to cut the center section to open the 6th tray for inspection. When cleaned, it can be welded back together and reinstalled (if needed). It may not be needed.

The column internals are relatively free of corrosion. There is discoloration but no serious pitting or evidence of chipping, spalling, or other damage to the alonized layer. This relieved our anxiety considerably for a fairly large quantity of black flaky material high in $\mathrm{Cr}$ and $\mathrm{Fe}$ (and with some $\mathrm{Ni}$ ) had washed out of the column. This now can be traced to the failed gas preheater elements. 
Following removal of the plugged section of the regeneration column run C-10 was initiated on 5/22/78. Immediate difficulties were experienced when another trace heater on the upper pot drain line failed. This caused a delay in starting salt flow of several hours while repairs were effected. When this line became operational, the venturi feed tank was filled in readiness to start the venturi scrubber. As this was attempted, it was discovered that a number of trace heaters on the venturi feed line had failed. Investigation disclosed that failure was due to a moderate salt leak through a split seam in the 1-in. pipe wall. The salt had destroyed heaters along a 2 -ft section of the line. At this point it was decided to terminate the run and repair the damage.

A replacement section of pipe has been fabricated and installed. Inspection of the failed pipe shows it has bulged in places and has ruptured due to internal pressures. This results from heating the salt filled line unevenly, producing melted salt in sections plugged off by still frozen salt. Enormous expansion forces can be generated. Wave cycled this line from ambient to operating temperatures when it was filled with salt at least ten times before. This is the only pipe failure experienced to date.

When the newly fabricated pipe was installed and covered with replacement trace heaters the entire line was rewired to break it into two circuits instead of one. For the most part the heaters were wired so the halves on both sides of the pipe are on separate circuits. In the event of a heater failure, one side of the pipe would still be heated and operation could be continued. In addition, these circuits and the upper pot drain circuits were wired through variable transformers to allow operation at lower voltages.

About a dozen additional thermocouples were installed on the venturi feed line. During the heating cycle of run $\mathrm{C}-11$, these were carefully monitored to establish the temperature profile along the line.

Run C-11 was intiated on 6/5/78 at 12:01 a.m. (midnight). Startup entails turning all trace heaters on and heating to preset temperatures at predetermined rates. All thermocuples must be checked for correct response. All circuits must be checked with a portable ammeter to see if the proper current is flowing. The data logger must be started to provide alarm and overtemperatures cut off protection. 
By 5:30 a.m. the gasifier had been started and fueled with $800 \mathrm{lb}$ of coke. By 12:00 noon salt flow to the venturi was initiated. Flow of salt to the regenerator was not started until 1:50 p.m. when the valve finally thawed. During the next 6 hours all'systems were operating. At 8:16 p.m. the upper siphon froze and salt feed to the regenerator was valved off. Salt circulation in the extraction section was continued and it was noted that the pressure drop across the venturi was becoming too high. Temperatures in the venturi exhaust line were increased and $\mathrm{CO}_{2}$ was introduced at approximately $4 \mathrm{cfm}$ to help suppress suspected carbon deposition. Shortly after midnight 6/6/78 salt flow to the regenerator was reestablished. At 1:55 a.m. salt flow to all sections was valved off, the gas was bypassed, air flow to the gasifier was reduced and the gasifier was refueled by addition of $200 \mathrm{lb}$ of coke.

By this time it has been determined that the pressure drop across the venturi was due to sludge buildup in the 2.5-in. venturi exhaust line. During this run we were operating with about one-half the normal salt inventory. We could not take a bleed stream off, for we were temporarily out of $\mathrm{Li}_{2} \mathrm{CO}_{3}$ needed for fresh salt makeup. Carbon deposition and particle accumulation had loaded the small volume of circulating salt excessively and the physical property change was enough to cause sludge buildup in the venturi exhaust. We needed more salt and we needed to clear the exhaust line.

$195 \mathrm{lb}$ of salt was salvaged from an overflow reservoir tank and added to the salt makeup tank. This almost doubled the volume on hand. The exhaust line was partially cleared by steam $/ \mathrm{CO}_{2}$ flushing followed by air flushing.

When it became clear that the line could be cleared, an additional $200 \mathrm{Ib}$ of coke and $200 \mathrm{lb}$ of coal were charged to the gasifier. A water injection port was installed in the upper part of the gasifier vessel to permit $\mathrm{H}_{2} \mathrm{O}$ addition (to help suppress C deposition). By 1:30 p.m. (6/6/78) operation was resumed by initiation of salt flow to the venturi. The extraction column was started but trouble was encountered getting the regenerator restarted and it was determined that the $\mathrm{H}_{2} \mathrm{~S}$ exhaust line was plugged. This had evidently occurred after midnight $(6 / 6 / 78)$ but before salt flow was valved off at 1:55 p.m. 
About 3 hours were required to dismantle and clear this line which, fortunately, was plugged over only a short distance. While this work was underway an additional 800 ib of coal were charged to the gasifier.

At 8:30 p.m. salt flow to the venturi was initiated and by 9:30 p.m. a1 systems were operating. Operation was continued until 5:30 a.m. when it became necessary to suspend salt flow, bypass gas flow and refuel the gasifier.

Malfunction of the secondary burner ignition and control system caused delay in getting restarted and it was 10:00 a.m. (6/7/78) before salt flow was resumed. During our preoccupation with the secondary burner problem we had not noticed that the gas preheater had tripped off (probably because purge gas flow was insufficient to prevent an overtemperature). As a result, salt flow at the venturi orifice stopped due to solidification at the cold area. These problems were cleared up about 1:20 p.m. and operation was continued until 8:30 p.m. when the salt flow was valved off to permit refueling the gasifier.

The gasifier had developed two severe leaks during the preceeding 12 hours while operating on coal. This is serious because with coal, tars are ejected along with the leaking gases. A major leak at the lower slide valve stem packing seal was accompanied by tar emissions. It seemed better to keep personnel clear of the area and continue operation until production of tars/oils ceased than to shut down and tackle the problem of dealing with tar contaminated material to be discharged and disposed of.

In view of this problem, it was decided to refuel with coke to avoid further tar emissions and by 10:30 p.m. $1020 \mathrm{lb}$ of. coke had been charged. Again, difficulty with ignition at the secondary burner was experienced and it was 1:15 a.m. (6/8/78) before salt flow to the venturi was initiated. N salt flow could be established to the regenerator and it was discovered that small trace heaters on the salt cooler as well as heaters on the salt recycle leg (coming out of the coarse de-entrainer) had failed. The insulation was removed in preparation to repair the heaters, but it was found that spare heaters had been damaged in shipment so we did not have enongh on hand to complete repairs. A postmortem also disclosed that minor salt seepage from Grayloc hubs had been responsible for the element failures. These flanges will have to be taken down and new seal rings installed before new trace heaters can be installed. It 
would not have been possible to effect immediate repairs. In any case, the decision was reached to shut down to effect repairs. Most of the freshly charged coke has been salvaged.

During run $\mathrm{C}-11$ the lower pot furnace tripped its breakers and had to be shut down. It was found to have two open and one shorted element. Connective wiring has been revised to allow continued operation of the furnace at about 67 percent of rated power--which is adequate.

During run $\mathrm{C}-11$, this furnace was off during much of the run. This led to an insidiuous problem which surfaced during run $\mathrm{C}-12$ which was initiated on 6/25/78. With this furnace off, sections of pipe below the venturi orifice which includes a 3-in. tee and, below this, a 6-in. slide valve, all run cool. These normally heat by radiation from this big furnace. Whenever gas flow to the venturi is bypassed, these parts cool because no hot gas is flowing. These factors combined to produce a cold spot on which salt could freeze. Each time flow to the venturi was stopped, a small amount of salt which has been climbing up the wall of the venturi exhaust line flowed back down and into the pot in this large furnace. The cold spot caused some of this to freeze and a plug began to form between the venturi orifice and the lower pot.

During run C-12 it was decided to jettison about $75 \mathrm{lb}$ of salt to the lower pot. This would be done by allowing salt flow to the venturi in the absence of gas flow. With no gas flow, the venturi floods and salt flows to the lower pot. As described above, the flow path to the lower pot had become partially plugged and the flowing salt built up sufficient head to flow up the 3-in. gas inlet line and into the gas preheater. Fortunately, the amount of salt which took this route (no more than 5 or $6 \ell$ ) was insufficient to reach the heating elements in this unit. The gas preheater was off and the presence of salt at the outlet of the gas preheater was sensed by the control thermocuple at that point.

An attempt was made to break a flange at the low point in the line and allow the unwanted salt to spill out, but the salt froze before this could be done. It was necessary to melt it out of the line and out of the gas preheater with an oxyacetylene torch and then reassemble the line. This required several hours. 
During run $\mathrm{C}-12$ the gasifier operated without problems but the secondary burner malfunctioned repeatedly. Plans to extensively remodel this unit are being formulated.

The gasifier was sperated for a period of 78 hours during run C-12. Simultaneous operation of all systems was less satisfactory than during run $\mathrm{C}-11$ due to difficulty in stabilizing (balancing) salt flows between the extraction and regeneration sections. Data from both runs $\mathrm{C}-11$ and $\mathrm{C}-12$ has not been completely analyzed.

\section{PROPOSED WORK DURING THE NEXT QUARTER}

Three more runs of the PDU are planned. Partial disassembly of key components and careful evaluation of corrosion/erosion phenomena which have occurred is also planned.

\section{OVERAL PROJECT STATUS}

Satisfactory completion of work during the next quarter should provide evidence that a scale-up of the PDU is feasible and desirable. Data so far generated by PDU operation are completely in accordance with prediction from theory and earlier laboratory and PDU operations. 


\section{DISTRIBUTION}

No. of

Copies

OFFSITE

A. A. Churm

DOE Chicago Patent Group

9800 South Case Avenue

Argonne, IL 60439

5 Dr. Michael Gurevich

D0E Fossil Energy

20 Massachusetts Avenue

Washington, DC 20545

27 DOE Technical Information Center
No. of

Copi es

GNSITE

2 DOE Richland Operations Office Program Division

Harold Ransom

20 Pacific Northwest Laboratory

C. H. Allen

G. A. Halseth

D. C. Hm

R. L. Maness

D. H. Mitchell

R. H. Moore (3)

R. E. Nightingale

C. A. Rohrmann

R. J. Robertus

G. L. Stegen

P. C. Walkup

Publishing Coordination (2)

Technical Information (5) 